\title{
Thonon-les-Bains - 26 chemin Vieux
}

Opération préventive de diagnostic (2013)

\section{Christophe Landry}

\section{(2) OpenEdition \\ Journals}

Édition électronique

URL : https://journals.openedition.org/adlfi/14965

ISSN : 2114-0502

Éditeur

Ministère de la Culture

Référence électronique

Christophe Landry, «Thonon-les-Bains - 26 chemin Vieux » [notice archéologique], ADLFI. Archéologie de la France - Informations [En ligne], Auvergne-Rhône-Alpes, mis en ligne le 29 mai 2015, consulté le 16 juin 2021. URL : http://journals.openedition.org/adlfi/14965

Ce document a été généré automatiquement le 16 juin 2021.

(c) ministère de la Culture et de la Communication, CNRS 


\title{
Thonon-les-Bains - 26 chemin Vieux
}

Opération préventive de diagnostic (2013)

\author{
Christophe Landry
}

\section{NOTE DE L'ÉDITEUR}

Organisme porteur de l'opération : Inrap

Le diagnostic mené en mars 2013, 26 chemin Vieux, en préalable à la construction d'un immeuble, a permis de mettre au jour une forte concentration de vestiges antiques au sein d'un sondage de $30 \mathrm{~m}^{2}$ situé entre une maison individuelle encore habitée et la rue dite du Chemin Vieux. Les niveaux antiques apparaissent sous 0,50 $\mathrm{m}$ de recouvrement. Le site est installé directement sur la terrasse tardi-würmienne dont la surface se trouve en ce point à l'altitude de 433,20 m NGF. L'épaisseur maximale de l'occupation reconnue atteint $0,80 \mathrm{~m}$. Deux états peuvent avoir existé, qu'un lot céramique homogène permet de caler vers la fin du $\mathrm{I}^{\mathrm{er}} \mathrm{s}$. apr. J.-C. Des aménagements sont à relier à une activité artisanale centrée sur la production métallurgique: une fosse se caractérise notamment par une très forte concentration de battitures et de déchets ferreux et la présence de petits fragments de paroi de four, ainsi que d'une meule à concasser le minerai. En l'état, ces éléments désignent potentiellement une phase d'épuration du métal, située entre la réduction du minerai et la forge dans la chaîne opératoire sidérurgique. Cinq murs, dont un probablement en terre, et un autre récupéré, sont implantés selon une trame orientée à $\mathrm{NL} 20^{\circ} \mathrm{O}$, définissant des espaces intérieurs et extérieurs, dans un secteur de l'agglomération antique voué à l'artisanat. $\mathrm{Si}$, un peu plus au nord, la production de céramique semble dominer, il semble bien que l'on soit ici en présence d'un atelier de métallurgie, dont la production reste à déterminer. Le site antique se prolonge sous l'emplacement de la maison et sous la rue, mais le reste de la parcelle, au sud et à l'ouest de la maison, s'est avéré vierge de toute trace d'occupation antérieure à l'époque moderne, période où le terrain était couvert de vignes. Les empreintes de ces cultures ont pu être mises au jour, sous la forme de quinze tranchées de défonçage comblées de galets. Cette parcelle s'avère une des 
dernières fenêtres conservées sur le passé antique du quartier, et les vestiges qu'elle recèle revêtent un intérêt certain pour la compréhension de l'artisanat du fer en contexte périurbain, activité encore mal connue pour le Haut-Empire dans la région du Bas-Chablais.

\section{INDEX}

Année de l'opération : 2013

chronologie https://ark.frantiq.fr/ark:/26678/pcrtxT02uJOogm, https://ark.frantiq.fr/ark:/ 26678/pcrtof7EHNsS2e, https://ark.frantiq.fr/ark:/26678/pcrtZTmusVUU24

nature https://ark.frantiq.fr/ark:/26678/pcrtWWQS75V5Bc

lieux https://ark.frantiq.fr/ark:/26678/pcrtSEeAipsBlD, https://ark.frantiq.fr/ark:/26678/ crtB8WDyqd6u9, https://ark.frantiq.fr/ark:/26678/pcrt5V2VjpTJWV, https://ark.frantiq.fr/ark:/ 26678/pcrt8fR8mwy7yM

sujets https://ark.frantiq.fr/ark:/26678/pcrt1DMOWvDF4j, https://ark.frantiq.fr/ark:/26678/ pcrttrEq4Rcpkr, https://ark.frantiq.fr/ark:/26678/pcrtD8bo5lH0H4, https://ark.frantiq.fr/ark:/ 26678/pcrtuf9JSs9vo6, https://ark.frantiq.fr/ark:/26678/pcrtKJVpuP3AET, https:// ark.frantiq.fr/ark:/26678/pcrtM9HMWQTGJV, https://ark.frantiq.fr/ark:/26678/ pcrtDpSNLz1mSr, https://ark.frantiq.fr/ark:/26678/pcrtIxHmbVwDYW

\section{AUTEURS}

\section{CHRISTOPHE LANDRY}

Inrap 